\title{
Bioactivity evaluation and phytochemical screening of Euphorbia helioscopia and Rumex dentatus
}

\author{
Shomaila MEHMOOD ${ }^{1}$, Fatima SYED ${ }^{2}$, Muhammad Issa KHAN ${ }^{3 *}$ (D), Rana Muhammad AADIL ${ }^{3}$
}

\begin{abstract}
Euphorbia helioscopia and Rumex dentatus are two essential medicinal plants that are widely used in traditional medicines against various illnesses. The present research was focused to confirm and validate the antibacterial, antifungal and antitumor activities of both plants. The antimicrobial activities were investigated against different bacterial and fungal strains. The in vitro antioxidant activities were confirmed against DPPH, hydroxyl and superoxide free radicals using ascorbic acid (Vc) as a standard. The results indicated that the increase in percentage scavenging activity is due to the increase in concentration of both plant extracts from 50-500 $\mu \mathrm{g} / \mathrm{mL}$. Moreover, the percentage tumor inhibition of both plant extracts was confirmed by potato disc method using dimethylsulfoxide (DMSO) as a negative control. The higher percentage of tumor inhibition was observed for water and ethanolic extract in case of E. helioscopia and $R$. dentatus, respectively.
\end{abstract}

Keywords: Euphorbia helioscopia; Rumex dentatus; antimicrobial; antitumor; phytochemical screening.

Practical Application: The research work will be helpful to explore the utilization potential of both plants after studying the antibacterial, antifungal, and antitumor activities. It will be helpful for nutraceutical and functional foods industries to utilize the findings of the research.

\section{Introduction}

There are about 6,000 higher plant species in Pakistan and about $10 \%$ of that has medical value. The medical practitioners are treating about $50 \%$ of the Pakistani population by using traditional medicines (Waheed et al., 2020). Medicinal plants are key sources of raw materials for both modern and traditional medicines and have been used to cure human ailments for many years. These medications serve as an important source of new bioactive compounds, such as antimicrobial agents (Batool et al., 2018).

Medicinal plants produce various secondary metabolites with significant variations in their structures and are useful for humans in various applications. Secondary metabolites are categorized as glycosides, alkaloids, phenolic compounds, terpenoids, tannins, volatile oils, saponins, resins, steroids, etc. Many of these secondary metabolites which are possibly true isolates, mixtures and chemically modified derivatives of plants are commercially significant and are used in flavoring, fragrances, and pharmaceutical formulations, worldwide (Padalia, 2012).

Plants contain valuable phytochemicals that act as antioxidants and are used as human food (Boots et al., 2008). Previous reports have revealed that plants contain vitamins, phenolic, and flavonoids compounds that are the primary source of antioxidants (Suffredini et al., 2004). Researchers have examined the influence of different types of solvents, such as ethyl alcohol, n-hexane, and methanol for the extraction of antioxidants from different parts of the plants. Hence, for the extraction of various phenolic compounds from plants with greater accuracy, different solvents with varying polarities should be used (Altemimi et al., 2017).

Euphorbia helioscopia belonging to the family, Euphorbiaceae, is also known as Sun spurge with ovoid alternate leaves, erected reddish stem, and yellowish-green flowers. It is widespread in Asia, Europe, and North Africa and has been considered as a medicinal plant used in traditional medicines around the world. In recent years, numerous secondary metabolites which include diterpenoids, tannins, and steroids have been recovered from this plant which marks it a highly bioactive herb. It possesses antifungal and antibacterial properties (Maoulainine et al., 2012) and has been used traditionally as medicines for curing different types of cancers, tumors, and warts for many years. Rumex dentatus belonging to Polygonaceae is generally known as dentate dock, Indian Dock, and Toothed Dock and are used traditionally as an anti-inflammatory, bactericidal, astringent, antitumor, anti-dermatitis, cholagogue, laxative, and diuretic agents (Nisa et al., 2013). These plants are also a rich source of secondary metabolites, hence acting as highly bioactive plants for drug manufacturing.

Researchers are progressively more interested in investigating new sources of natural medicines. When the literature studies are examined, it is seen that researchers related to the evaluation of solvent-based extracts obtained from plants and their biological 
activities have gained more importance in recent years. Therefore, in this study, we aimed to assess the antimicrobial, antifungal, and in vitro antioxidant properties against DPPH, superoxide, and hydroxyl radicals of n-hexane, DCM, ethanol, and water extracts of E. helioscopia and Rumex dentatus in details from Kohat region, Pakistan. We have also examined the effect of increasing polaritybased extraction on the bioactivities of both plants. Moreover, the phytochemicals present in both plants have also been investigated in order to evaluate their medicinal importance.

\section{Materials and methods}

\subsection{Study area}

The study area selected is Kohat which is the city in Khyber Pakhtunkhwa, Pakistan and is located at an altitude of 489 metres $(1,604 \mathrm{ft})$.

\subsection{Collection of plant material}

Plants used for evaluation of their bioactivities (E. helioscopia and Rumex dentatus) were collected from District Kohat in the month of January and were identified in Department of Botany, University of Peshawar, Pakistan. After identification, plants were washed for cleaning, dried, and then ground to fine powder using grinder. A weighted amount of 20-25 g of the ground material from both plants was used for solvent-based extraction.

\subsection{Extraction}

Plant materials (20-25 g) were extracted with solvents (n-hexane, DCM, ethanol, and water) on the polarity basis. The continuous Soxhlet apparatus was used for the extraction. A weighed amount of the ground material was taken in a thimble, suspended above the flask filled with a solvent with a reflux condenser fitted. The flask was heated on the heating mantle for 3-4 hours at a temperature of $60-65^{\circ} \mathrm{C}$. The solvent evaporated upon condensation trickled on the plant material in the extraction chamber. When the solvent exceeded a certain level over the sample, it trickled down back into the boiling flask. The process was repeated and then the flask contains the extract was removed for evaporation of the solvent.

The solvent was evaporated by a rotary evaporator under vacuum and the plant extract was collected and the resulting crude extracts were stored at $4{ }^{\circ} \mathrm{C}$ in labelled glass vials. For the assessment of biological activities, a known amount of the extract was taken for each assay.

\subsection{Selected strains (bacterial and fungal)}

Five bacterial and five fungal strains were selected for the study. Staphylococcus aureus, Bacillus subtilis, Pseudomonas picketti, Escherichia coli and Micrococcus luteus and fungal strains used were Fusarium solani, Trichoderma harzianum, Alternaria alternata, Rhizopus nigricans and Aspergillus fumigatus.

\subsection{Sterilization of equipment}

All the experimental equipment (beakers, Petri-dishes, borers, test tubes, micropipette tips, Eppendorf tubes, and media) were decontaminated for 15 minutes in an autoclave at a temperature and pressure of $121^{\circ} \mathrm{C}$ and $15 \mathrm{Ibs} / \mathrm{sq}$ inch. respectively. The Laminar chamber was sterilized with ethanol solution ( $75 \%, 75 \%$ ethyl alcohol in $25 \%$ distilled water). The loops for bacterial inoculation were sterilized on spirit lamp fire. The whole experimental work was performed in the laminar hood in order to prevent contamination.

\subsection{Evaluation of antibacterial activity}

Antibacterial activities of both the plant extracts were evaluated using the agar well diffusion method as reported by Carron et al. (1987). All the bacterial strains were first cultured on nutrient broth and then incubated for 24 hours before the experiment. Nutrient agar was melted, cooled to $40^{\circ} \mathrm{C}$, and poured into decontaminated Petri-dishes. Wells were made in the media with sterile metallic borer having a diameter of $6 \mathrm{~mm}$ and keeping $24 \mathrm{~mm}$ distance between two adjacent wells. The 4-8 hour old bacterial cultures were inoculated on the surface of the nutrient agar with the disinfected cotton swab.

\subsection{Sample loading and control}

The plant extracts $(100 \mu \mathrm{L})$ having concentration of $22 \mathrm{mg} / \mathrm{mL}$ dissolved in DMSO $(1 \mathrm{~mL})$ was added to each well using DMSO $(100 \mu \mathrm{L})$ as a negative control and Streptomycin ( $2 \mathrm{mg} / \mathrm{mL}$ dissolved in DMSO) as a positive control. The culture plates were then incubated for 24 hours at $37^{\circ} \mathrm{C}$ and next day activity was noted in terms of zone of inhibition (ZOI) in $\mathrm{mm}$ by using a simple scale. The reference positive control was used to calculate growth inhibition (\%) by using the following equation:

$\%$ Inhibition $=\frac{\text { Zone of inhibition of sample }}{\text { Zone of inhibition of } \text { standard }} \times 100$

\subsection{Evaluation of antifungal activity}

The antifungal activity was assessed using the procedure reported by Humeera et al. (2013), with minor alterations. Sabouraud dextrose agar (SDA) media were prepared, sterilized, and poured into plates for 24 hours at $28^{\circ} \mathrm{C}$. The next day plants were inoculated with fungal strains and incubated at $28^{\circ} \mathrm{C}$ for 7 days to get a week-old culture as per need of an experimental plan. $5 \mathrm{~mL}$ autoclaved SDA media was added to the test tubes to prepare slants and the test tubes were then retained in an inclined position to solidify. After 24 hours of sterility check, inoculums from 7 days old cultures were applied to respective slants. The test tubes were incubated for 7 days and results were determined by calculating the linear development on the test tubes to calculate the zone of inhibition (ZOI).

\subsection{In vitro antioxidant assays}

\section{$D P P H$ radical scavenging assay}

The antioxidant activity of the extracts of both of the plants was measured with 1,1-diphenyl 2-picryl hydrazyl radical (DPPH) using a spectrophotometer at a wavelength of $517 \mathrm{~nm}$, with minor alterations (Blois, 1958). The stock solutions of both the plant 
extracts ( $5 \mathrm{mg} / \mathrm{mL}$, stock solution) were prepared by dissolving extract in a $10 \%$ aqueous solution of DMSO. Different working concentrations $(50,100,200,400$ and $500 \mu \mathrm{g} / \mathrm{mL})$ of all the extracts were prepared from the stock solutions (extracts of both plants in different solvents) using suitable dilution. The percentage scavenging was the activity calculated by decolorization of DPPH solution from violet to light yellow, while ascorbic acid (Vc) was used as a positive control.

\section{Superoxide radical scavenging assay}

The superoxide radical scavenging activity of extracts of both plants were calculated by the reported method (Liu et al., 1997) spectrophotometrically at a wavelength of $590 \mathrm{~nm}$, with minor modifications. Phosphate buffer (also taken as control) was used as blank after illumination for $5 \mathrm{~min}$.

\section{Hydroxyl radical scavenging assay}

The colorimetric deoxyribose (thiobarbituric acid reactive substance) (TBARS) method was used as the standard method of comparison for the determination of hydroxyl radical scavenging activity of extracts of both plants (Soobrattee et al., 2008) at a wavelength of $532 \mathrm{~nm}$, with minor modifications.

\section{Tumor inhibition assay}

Antitumor activities of $\mathrm{n}$-hexane, dichloromethane, ethanol and water extracts of E. helioscopia and Rumex dentatus, were investigated by potato disc method using Vincristine sulfate as a positive and DMSO as a negative control. The protocol followed was according to Ashraf et al. (2015) while the percent inhibition was measured by the formula used by Kanwal et al. (Ahmad \& Beg, 2001), given as:

$$
\text { Percentage inhibition }=(1-N s / N c) \times 100
$$

whereas, Ns represents the average number of tumors in sample and Nc represents the average number of tumors in negative control.

\subsection{Phytochemical screening}

Phytochemical screening of both plant extracts was performed following standard qualitative methods.

\subsection{Alkaloids}

Plant extract $(0.2 \mathrm{~g})$ was warmed with $2 \% \mathrm{H}_{2} \mathrm{SO}_{4}$ for 24 minutes, filtered and few drops of Dragendrof's reagent were added and orange red precipitate indicated the presence of alkaloids (Muhammad et al., 2012).

\subsection{Tannins}

Plant extract $(0.2 \mathrm{~g})$ was mixed with water, heated, and filtered. The filtrate was added with few drops of ferric chloride and dark green coloration indicated the presence of tannins.

\subsection{Flavonoids}

Plants extract $(0.2 \mathrm{~g})$ was dissolved in $10 \% \mathrm{NaOH}$ and $2 \mathrm{M} \mathrm{HCl}$. Flavonoid's presence is indicated by discoloration of yellow solution.

\subsection{Steroids}

The acetic anhydride $(2 \mathrm{~mL})$ was added to $0.5 \mathrm{~g}$ of each extract and then $2 \mathrm{~mL}$ of $\mathrm{H}_{2} \mathrm{SO}_{4}$ was added. The change in color from violet to blue or green or red identified the presence of steroids (Muhammad et al., 2012).

\subsection{Reducing sugars}

About $2 \mathrm{~mL}$ of ethanolic extract, $5 \mathrm{~mL}$ of the mixture (1:1) of Fehling's solution (A) and Fehling's solution (B) was added and the mixture was boiled in a water bath for 5 minutes. A brick-red precipitate indicated the presence of reducing sugars.

\subsection{Saponins}

The ethanolic plant extract $(0.5 \mathrm{~g})$ was taken in a test tube and dissolved in a $10 \mathrm{~mL}$ distilled water. The test tubes were vigorously shaken for 30 seconds and then allowed to stand for $45 \mathrm{~min}$. The presence of saponins is confirmed by the appearance of foaming which persists on warming.

\subsection{Anthraquinones}

Plant extract $(0.5 \mathrm{~g})$ was mixed with $10 \mathrm{~mL}$ benzene, filtered and then $5 \mathrm{~mL}$ ammonia solution (10\%) was added to the filtrate and the mixture was shaken. The presence of anthraquinones is confirmed by the appearance of pink, red, or violet color in the ammoniacal (lower) phase.

\section{Results}

\subsection{Antibacterial activity analysis}

The antibacterial activities of crude extracts of the selected plants (Euphorbia helioscopia and Rumex dentatus) in n-hexane, DCM, ethanol, and water against different bacterial strains were investigated. DMSO was used as a negative control as no inhibition was recorded by it against all the used bacterial strains. Streptomycin (a positive control) was used as a standard against the bacterial strains represented the highest activity i.e., the zone of inhibition (calculated by using Equation 1 ) as shown in Tables 1 and 2. All the extracts particularly water and ethanolic extracts have shown considerable activities against the bacterial strains. Our results indicated that the zone of inhibition was considerably affected by the plant extracts.

It can be seen from the data depicted in Table 1, that the highest zone of inhibition was observed by water and ethanolic extracts. The percent zone inhibition of water extract was higher against Pseudomonas picketii (91.66\%), E. coli (90\%), and Staphylococcus aureus $(61.76 \%)$ whereas, the ethanolic extract has shown the highest percentage zones of inhibition against M. luteus (66.66\%) and Bacillus (57.69\%) species. DCM and $\mathrm{n}$-hexane extracts followed water and ethanolic extracts in 
Table 1. Zone of inhibition ( $\mathrm{mm}$ ) for Euphorbia helioscopia extracts against different bacterial strains and \% inhibition compared to Streptomycin.

\begin{tabular}{|c|c|c|c|c|c|c|c|c|c|c|}
\hline \multirow{2}{*}{ Bacterial Strain } & \multirow{2}{*}{$\begin{array}{c}\text { ZOI (mm) } \\
\text { Streptomycin } \\
\text { (Positive control) }\end{array}$} & \multirow{2}{*}{$\begin{array}{l}\text { ZOI (mm) DMSO } \\
\text { (Negative control) }\end{array}$} & \multicolumn{2}{|c|}{ n-hexane } & \multicolumn{2}{|c|}{ DCM } & \multicolumn{2}{|c|}{ Ethanol } & \multicolumn{2}{|c|}{ Water } \\
\hline & & & ZOI & $\%$ Inhibition & ZOI & \% Inhibition & ZOI & \% Inhibition & ZOI & $\%$ Inhibition \\
\hline Staph. aureus & 34 & -- & 7 & 20.58 & 12 & 35.29 & 18 & 52.94 & 21 & 61.76 \\
\hline Bacillus subtilis & 26 & -- & 5.2 & 20 & 13 & 50 & 15 & 57.69 & 13 & 50 \\
\hline Pseudomonas picketii & 24 & -- & 3 & 12.5 & 15 & 62.5 & 21 & 87.7 & 22 & 91.66 \\
\hline E.coli & 20 & -- & 0 & 0 & 12 & 60 & 17 & 85 & 18 & 90 \\
\hline M. luteus & 33 & -- & 9 & 27.27 & 14 & 42.42 & 22 & 66.66 & 20 & 60.60 \\
\hline
\end{tabular}

Table 2. Zone of inhibition ( $\mathrm{mm}$ ) and percent inhibition by Rumex dentatus extracts against different bacterial strains compared to standard Streptomycin.

\begin{tabular}{|c|c|c|c|c|c|c|c|c|c|c|}
\hline \multirow{2}{*}{ Bacterial Strain } & \multirow{2}{*}{$\begin{array}{c}\text { ZOI (mm) } \\
\text { Streptomycin } \\
\text { (Positive control) }\end{array}$} & \multirow{2}{*}{$\begin{array}{c}\text { ZOI }(\mathrm{mm}) \\
\text { DMSO } \\
\text { (Negative control) }\end{array}$} & \multicolumn{2}{|c|}{ n-hexane } & \multicolumn{2}{|c|}{ DCM } & \multicolumn{2}{|c|}{ Ethanol } & \multicolumn{2}{|c|}{ Water } \\
\hline & & & $\mathrm{ZOI}$ & \% Inhibition & $\mathrm{ZOI}$ & \% Inhibition & $\mathrm{ZOI}$ & \% Inhibition & $\mathrm{ZOI}$ & \% Inhibition \\
\hline Staph. aureus & 34 & -- & 18 & 52.94 & 26 & 76.47 & 30 & 88.23 & 32 & 94.11 \\
\hline Bacillus subtilis & 26 & -- & 9.5 & 36.53 & 11 & 42.30 & 17 & 65.38 & 15 & 57.69 \\
\hline Pseudomonas picketii & 24 & -- & 15 & 62.5 & 17 & 70.8 & 19 & 79.16 & 20 & 83.33 \\
\hline E.coli & 20 & -- & 8 & 40 & 11 & 55 & 16 & 80 & 19 & 95 \\
\hline M. luteus & 33 & -- & 5 & 15.15 & 15 & 45.45 & 12 & 36.36 & 11 & 33.33 \\
\hline
\end{tabular}

Table 3. Zone of inhibition ( $\mathrm{mm}$ ) and percent inhibition by Euphorbia helioscopia extracts against different fungal strains compared to standard Streptomycin.

\begin{tabular}{|c|c|c|c|c|c|c|c|c|c|c|}
\hline \multirow[b]{2}{*}{ Fungal Strain } & \multirow{2}{*}{$\begin{array}{c}\mathrm{ZOI}(\mathrm{mm}) \\
\text { Streptomycin } \\
\text { (Positive control) }\end{array}$} & \multirow{2}{*}{$\begin{array}{l}\text { ZOI (mm) DMSO } \\
\text { (Negative control) }\end{array}$} & \multicolumn{2}{|c|}{ n-hexane } & \multicolumn{2}{|c|}{ DCM } & \multicolumn{2}{|c|}{ Ethanol } & \multicolumn{2}{|c|}{ Water } \\
\hline & & & $\mathrm{ZOI}$ & $\begin{array}{c}\% \\
\text { Inhibition } \\
\end{array}$ & $\mathrm{ZOI}$ & $\begin{array}{c}\% \\
\text { Inhibition } \\
\end{array}$ & $\mathrm{ZOI}$ & $\begin{array}{c}\% \\
\text { Inhibition }\end{array}$ & $\mathrm{ZOI}$ & $\begin{array}{c}\% \\
\text { Inhibition }\end{array}$ \\
\hline Fusarium solani & 30 & -- & 16 & 53.33 & 18 & 60 & 22 & 73.33 & 26 & 86.66 \\
\hline Trichoderma harzianum & 20 & -- & 14 & 70 & 16 & 80 & 19 & 95 & 17 & 85 \\
\hline Alternaria alternata & 21 & -- & 13 & 61.90 & 17 & 80.95 & 18 & 85.71 & 19 & 90.47 \\
\hline Rhizopus nigricans & 19 & -- & 12 & 63.15 & 15 & 78.94 & 16 & 84.21 & 17 & 89.47 \\
\hline Aspergillus fumigatus & 22 & -- & 14 & 63.63 & 16.7 & 75.90 & 17 & 77.27 & 19 & 86.36 \\
\hline
\end{tabular}

Table 4. Zone of inhibition $(\mathrm{mm})$ and percent inhibition by Rumex dentatus extracts against different fungal strains compared to standard Streptomycin.

\begin{tabular}{|c|c|c|c|c|c|c|c|c|c|c|}
\hline \multirow[b]{2}{*}{ Fungal Strain } & \multirow{2}{*}{$\begin{array}{c}\text { ZOI }(\mathrm{mm}) \\
\text { Streptomycin } \\
\text { (Positive control) }\end{array}$} & \multirow{2}{*}{$\begin{array}{l}\mathrm{ZOI}(\mathrm{mm}) \mathrm{DMSO} \\
\text { (Negative control) }\end{array}$} & \multicolumn{2}{|c|}{ n-hexane } & \multicolumn{2}{|c|}{$\mathrm{DCM}$} & \multicolumn{2}{|c|}{ Ethanol } & \multicolumn{2}{|c|}{ Water } \\
\hline & & & ZOI & $\begin{array}{c}\% \\
\text { Inhibition }\end{array}$ & ZOI & $\begin{array}{c}\% \\
\text { Inhibition }\end{array}$ & ZOI & $\begin{array}{c}\% \\
\text { Inhibition }\end{array}$ & $\mathrm{ZOI}$ & $\begin{array}{c}\% \\
\text { Inhibition }\end{array}$ \\
\hline Fusarium solani & 30 & -- & 14 & 33.3 & 11.6 & 38.66 & 22 & 73.33 & 24 & 80 \\
\hline Trichoderma harzianum & 20 & -- & 13 & 65 & 14 & 70 & 18 & 90 & 17 & 85 \\
\hline Alternaria alternata & 21 & -- & 14 & 66.66 & 16 & 76.10 & 17 & 80.95 & 18.5 & 88.09 \\
\hline Rhizopus nigricans & 19 & -- & 11.5 & 60.52 & 12 & 63.15 & 16 & 84.21 & 18 & 89.47 \\
\hline Aspergillus fumigatus & 22 & -- & 11 & 50 & 10.5 & 47.72 & 16 & 72.72 & 17 & 77.27 \\
\hline
\end{tabular}

antibacterial activities. However, n-hexane extract did not show any activity against $E$. coli. strain.

The data in Table 2 shows the antibacterial activity of different extracts of Rumex dentatus. The highest activity in terms of percent zone of inhibition was recorded by water extract against E. coli (95\%), Staphylococcus aureus (94.11\%), and Pseudomonas picketii (83.33\%), whereas ethanolic extract exhibits the highest activity against Bacillus (65.38\%) and M. luteus (36.36\%) species.

It is concluded from the above data that $\mathrm{n}$-hexane extracts of both the plant materials are showing lowest percent zone of inhibition against all the bacterial strains while the highest percent zone of inhibition was displayed by the water and ethanolic extracts.

\subsection{Antifungal activity analysis}

Antifungal activity of the extracts of both plants was confirmed against different fungal strains. DMSO (used as negative control) did not show any activity while Streptomycin exhibited the highest zone of inhibition against all the fungal strains. The antifungal activity shown by the different extracts is represented in Tables 3 and 4 . The antifungal activity of E. helioscopia plant extracts have been explicated in Table 3 . 
The highest percent zone of inhibition was shown by water extract against Alternaria alternate (90.47\%), Rhizopus nigricans (89.47\%), Fusarium solani (86.66\%), and Aspergillus fumigatus (86.36\%) while ethanolic extract shows the highest activity against Trichoderma harzianum (95\%). DCM shows the highest zone of inhibition after ethanolic and water extract, while n-hexane shows the lowest activity against all the fungal strains.

The data in Table 4, indicated that the highest antifungal activity in terms of their respective percent zone of inhibition is shown by water extract of Rumex dentatus against Rhizopus nigricans (89.47\%), Alternaria alternate (88.09\%), Fusarium solani (80\%), and Aspergillus fumigatus (77.27\%) Similarly, an ethanolic extract shows the highest antifungal activity against Trichoderma harzianum (90\%) as compared to water (85\%). DCM extract shows the highest activity after water and ethanol followed by the $\mathrm{n}$-hexane extract. The results show that better antibacterial and antifungal activity with the highest percentage zones is shown by ethanolic and water extracts followed by DCM extract, while the lowest activity was recorded for $n$-hexane extract in the case of both plants. The antibacterial and antifungal potential of both plants can be attributed to the different bioactive constituents occurring in these plants (Ashraf et al., 2015).

\subsection{In vitro antioxidant activity of E. helioscopia}

The antioxidant potential of n-hexane, DCM, ethanolic, and water of E. helioscopia was assessed on the basis of their capability to scavenge stable free DPPH radicals and was compared with the standard antioxidant activity of ascorbic acid $(\mathrm{Vc})$. In the present study, the antioxidant activity of the extracts was evaluated in a dose-dependent manner $(50-500 \mu \mathrm{g} / \mathrm{mL})$ as shown in Tables 5 and 6 . The increasing trend in DPPH scavenging ability was attributed to the increase

Table 5. The percentage scavenging of different extracts of E. helioscopia against DPPH, hydroxyl and superoxide radicals using ascorbic acid $(\mathrm{Vc})$ as a standard.

\begin{tabular}{|c|c|c|c|c|c|c|}
\hline \multirow{2}{*}{ Antioxidant assay } & \multirow{2}{*}{ Solvent Extracts } & \multicolumn{5}{|c|}{ Concentrations $\mu \mathrm{g} / \mathrm{mL}$} \\
\hline & & 50 & 100 & 200 & 400 & 500 \\
\hline \multirow[t]{5}{*}{ DPPH assay } & n-hexane & - & - & $36.86 \pm 2.48$ & $44.63 \pm 0.80$ & $48.8 \pm 1.24$ \\
\hline & DCM & $39.49 \pm 1.67$ & $44.71 \pm 0.81$ & $49.66 \pm 0.71$ & $55.79 \pm 1.28$ & $57.44 \pm 0.10$ \\
\hline & Ethanol & $59.13 \pm 0.45$ & $62.58 \pm 0.88$ & $67.00 \pm 1.10$ & $71.36 \pm 0.53$ & $74.53 \pm 1.01$ \\
\hline & Water & $64.91 \pm 0.61$ & $67.75 \pm 0.44$ & $70.86 \pm 0.49$ & $77.01 \pm 0.65$ & $79.14 \pm 0.73$ \\
\hline & $\mathrm{Vc}$ & $68.99 \pm 0.69$ & $75.8 \pm 0.48$ & $79.99 \pm 1.19$ & $86.55 \pm 1.05$ & $86.74 \pm 0.69$ \\
\hline \multirow{5}{*}{$\begin{array}{l}\text { Hydroxyl radical } \\
\text { scavenging }\end{array}$} & n-hexane & - & - & - & $28.06 \pm 0.60$ & $33.51 \pm 0.49$ \\
\hline & DCM & - & - & $36.78 \pm 1.87$ & $43.74 \pm 0.87$ & $49.62 \pm 1.28$ \\
\hline & Ethanol & $45.39 \pm 0.47$ & $49.80 \pm 0.33$ & $54.06 \pm 0.74$ & $57.96 \pm 0.69$ & $63.33 \pm 0.44$ \\
\hline & Water & $51.31 \pm 0.37$ & $56.69 \pm 1.15$ & $61.44 \pm 0.66$ & $64.87 \pm 0.67$ & $66.69 \pm 0.88$ \\
\hline & $\mathrm{Vc}$ & $69.28 \pm 0.54$ & $74.75 \pm 0.83$ & $77.58 \pm 1.06$ & $85.94 \pm 0.72$ & $86.14 \pm 0.63$ \\
\hline \multirow{5}{*}{$\begin{array}{l}\text { Superoxide radical } \\
\text { scavenging }\end{array}$} & n-hexane & - & - & $36.95 \pm 1.14$ & $41.66 \pm 0.51$ & $43.28 \pm 1.17$ \\
\hline & DCM & - & - & $37.35 \pm 0.46$ & $46.33 \pm 1.15$ & $51.40 \pm 0.71$ \\
\hline & Ethanol & $51.45 \pm 1.42$ & $55.02 \pm 0.55$ & $57.58 \pm 0.22$ & $59.16 \pm 0.61$ & $61.42 \pm 0.99$ \\
\hline & Water & $50.50 \pm 0.89$ & $52.3 \pm 0.39$ & $58.57 \pm 0.36$ & $62.45 \pm 1.20$ & $64.72 \pm 1.80$ \\
\hline & $\mathrm{Vc}$ & $70.98 \pm 0.07$ & $73.76 \pm 0.59$ & $76.87 \pm 0.67$ & $78.95 \pm 0.90$ & $85.1 \pm 0.94$ \\
\hline
\end{tabular}

Table 6. The percentage scavenging of different extracts of Rumex dentatus against DPPH, hydroxyl and superoxide radicals using ascorbic acid $(\mathrm{Vc})$ as a standard.

\begin{tabular}{|c|c|c|c|c|c|c|}
\hline \multirow{2}{*}{ Antioxidant assay } & \multirow{2}{*}{ Solvent extracts } & \multicolumn{5}{|c|}{ Concentrations $\mu \mathrm{g} / \mathrm{mL}$} \\
\hline & & 50 & 100 & 200 & 400 & 500 \\
\hline \multirow[t]{5}{*}{ DPPH assay } & n-hexane & - & - & - & $36.36 \pm 1.11$ & $49.77 \pm 1.34$ \\
\hline & DCM & - & - & $37.75 \pm 0.08$ & $46.74 \pm 0.68$ & $55.44 \pm 1.11$ \\
\hline & Ethanol & $46.83 \pm 0.88$ & $55.32 \pm 1.30$ & $60.84 \pm 0.69$ & $67.73 \pm 0.64$ & $74.80 \pm 1.83$ \\
\hline & Water & $45.66 \pm 1.15$ & $53.95 \pm 1.27$ & $60.00 \pm 0.57$ & $65.36 \pm 0.94$ & $72.76 \pm 0.39$ \\
\hline & $\mathrm{Vc}$ & $97.08 \pm 0.22$ & $97.20 \pm 0.23$ & $97.42 \pm 0.53$ & $97.69 \pm 0.43$ & $98.60 \pm 0.50$ \\
\hline \multirow{5}{*}{$\begin{array}{l}\text { Hydroxyl radical } \\
\text { scavenging }\end{array}$} & n-hexane & - & - & - & - & $32.25 \pm 1.48$ \\
\hline & DCM & - & $37.40 \pm 0.95$ & $43.07 \pm 2.07$ & $48.85 \pm 1.88$ & $51.91 \pm 0.46$ \\
\hline & Ethanol & $52.74 \pm 0.71$ & $57.71 \pm 1.54$ & $61.42 \pm 1.01$ & $64.42 \pm 0.94$ & $66.57 \pm 2.64$ \\
\hline & Water & $46.83 \pm 0.88$ & $55.32 \pm 1.30$ & $60.84 \pm 0.69$ & $67.73 \pm 0.64$ & $74.80 \pm 1.83$ \\
\hline & $\mathrm{Vc}$ & $76.94 \pm 1.58$ & $79.44 \pm 0.47$ & $81.22 \pm 1.03$ & $87.37 \pm 1.03$ & $87.96 \pm 0.81$ \\
\hline \multirow{5}{*}{$\begin{array}{l}\text { Superoxide radical } \\
\text { scavenging }\end{array}$} & n-hexane & - & - & - & - & $31.55 \pm 0.49$ \\
\hline & DCM & - & - & $37.49 \pm 0.57$ & $47.87 \pm 0.48$ & $52.67 \pm 0.51$ \\
\hline & Ethanol & $56.29 \pm 0.58$ & $58.03 \pm 0.53$ & $62.95 \pm 1.32$ & $65.72 \pm 1.32$ & $71.34 \pm 0.60$ \\
\hline & Water & $59.20 \pm 0.58$ & $63.51 \pm 0.64$ & $64.35 \pm 0.61$ & $66.90 \pm 0.81$ & $72.32 \pm 1.50$ \\
\hline & $\mathrm{Vc}$ & $68.99 \pm 0.69$ & $75.8 \pm 0.48$ & $79.99 \pm 1.19$ & $86.55 \pm 1.05$ & $86.74 \pm 0.69$ \\
\hline
\end{tabular}


in the concentration of extracts, which is in the agreement with a previous report (Öztürk et al., 2011).

The DPPH scavenging ability of water extract of E. helioscopia $(79.14 \pm 0.73 \%)$ was higher than ethanolic extract $(74.53 \pm 1.01 \%)$ at $500 \mu \mathrm{g} / \mathrm{mL}$, followed by DCM (57.44 $\pm 0.10 \%)$ and n-hexane $(48.8 \pm 1.24 \%)$ at the same concentration. For hydroxyl radical scavenging activity, the highest percentage of scavenging was shown by water $(66.69 \pm 0.88 \%)$, followed by an ethanolic extract $(63.33 \pm 0.44 \%)$. The DCM extract showed the minimum percentage of scavenging of hydroxyl radicals (49.62 $\pm 1.28 \%$ ), whereas, $n$-hexane extract percent scavenging $(33.51 \pm 0.49 \%)$ did not represent considerable activity compared to standard ascorbic acid. For superoxide radicals, water extract $(500 \mu \mathrm{g} / \mathrm{mL})$ displayed the highest percentage of scavenging $(64.72 \pm 1.80 \%)$, followed by an ethanolic extract (61.42 $\pm 0.99 \%)$. Whereas, DCM and $\mathrm{n}$-hexane extract shows the lesser value of percentage scavenging of superoxide radicals $(51.40 \pm 0.71 \%$ and $43.28 \pm$ $1.17 \%$, respectively). It can be elucidated that $n$-hexane extract is showing very little or no percentage scavenging for all the three radicals at much lower concentrations $(50-200 \mu \mathrm{g} / \mathrm{mL})$.

\subsection{In vitro antioxidant activity of Rumex dentatus}

The in vitro antioxidant activity of all the extracts of Rumex dentatus was investigated against DPPH, hydroxyl, and superoxide radicals using ascorbic acid as a standard. Different concentrations exhibited different percentage of scavenging against different radicals in a dose-dependent manner. The scavenging activity increased as the concentration was increased from $50-500 \mu \mathrm{g} / \mathrm{mL}$. As presented in Table 6 data shows, that the highest percentage scavenging against DPPH radicals was shown by an ethanolic extract $(74.80 \pm 1.83 \%)$, followed by water $(72.76 \pm 0.39 \%)$, $\operatorname{DCM}(55.44 \pm 1.11 \%)$, and hexane extract $(49.77 \pm 1.34 \%)$ at a concentration of $500 \mu \mathrm{g} / \mathrm{mL}$. For hydroxyl radicals, the highest percentage of scavenging was recorded by water $(74.80 \pm 1.83 \%)$, followed by ethanol $(66.57 \pm 2.64 \%)$, DCM $(51.91 \pm 0.46 \%)$, and $\mathrm{n}$-hexane extract $(32.25 \pm 1.48 \%)$, at $500 \mu \mathrm{g} / \mathrm{mL}$. The percentage scavenging decreased at lower concentrations of the extracts. On the other hand, the highest percentage of scavenging against superoxide radicals was shown by water $(72.32 \pm 1.50 \%)$ followed by ethanol $(71.34 \pm 0.60 \%), \operatorname{DCM}(52.67 \pm 0.51 \%)$, and $n$-hexane extract $(31.55 \pm 0.49 \%)$ at $500 \mu \mathrm{g} / \mathrm{mL}$ concentration.

\subsection{Antitumor activity of E. helioscopia}

The antitumor activity of different concentrations $(50-500 \mu \mathrm{g} / \mathrm{mL})$ of E. helioscopia extracts of n-hexane, DCM, ethanol, and water have been investigated using the potato disc method. As shown in Figure 1a, that percentage tumor inhibition increased with the increase in the concentration of plant extract.

Twenty-seven tumors were observed on the potato discs inoculated in DMSO extract (negative control) and percent tumor inhibition was calculated using Equation 2. The water extract presented the highest percentage of tumor inhibition $(72.33 \pm 0.57 \%)$ followed by ethanol $(63.33 \pm 2.51 \%)$, DCM $(42.66 \pm 3.21 \%)$, and $n$-hexane $(30 \pm 2.82 \%)$ at $500 \mu \mathrm{g} / \mathrm{mL}$.

\subsection{Antitumor activity of Rumex dentatus}

The antitumor activity of Rumex dentatus extracts presented a similar trend of tumor inhibition percentage in a concentrationdependent manner. However, it can be seen from the data elucidated in Figures 1b, that the highest tumor inhibition percentage was recorded for ethanolic extract $(63.53 \pm 3.53 \%)$ followed by water $(61 \pm 2.82 \%), \mathrm{DCM}(45.66 \pm 2.08 \%)$, and $\mathrm{n}$-hexane extract $(31.33 \pm 1.52 \%)$ at $500 \mu \mathrm{g} / \mathrm{mL}$.

\subsection{Phytochemical screening}

The phytochemical analysis confirmed the presence and absence of different phytochemicals in extracts of both plants as shown in Table 7.

\section{Discussions}

Plants provide a huge range of natural compounds that belong to diverse molecular families and offer various therapeutic properties. Two medicinal plants selected in the present study have been used traditionally for various medicinal purposes in

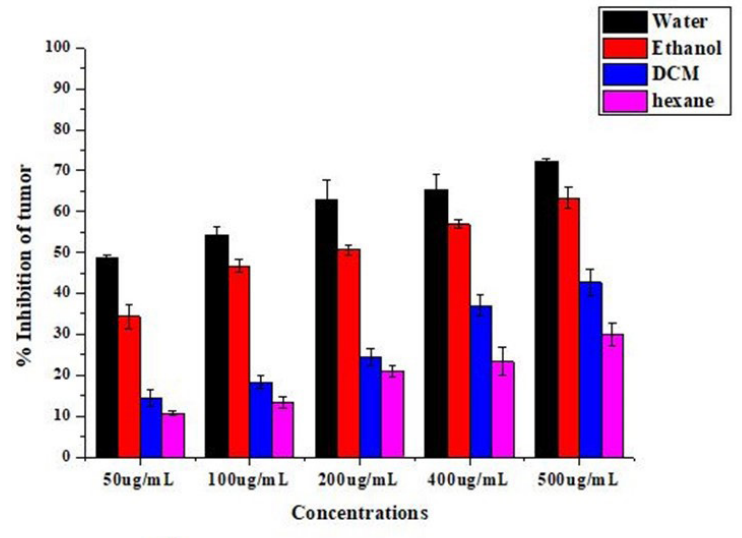

a)

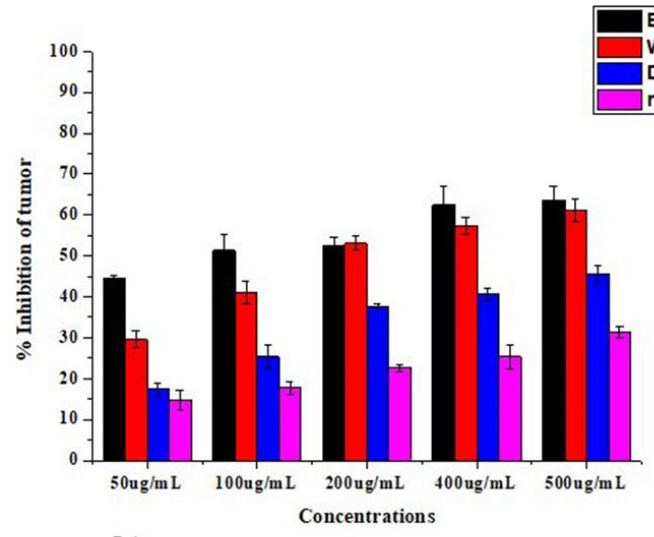

b)

Figure 1. The percentage tumor inhibition of E. helioscopia (a) and Rumex dentatus (b) extracts in concentration-dependent manner. The highest percentage inhibition of tumor is increased by increasing concentration from $50-500 \mu \mathrm{g} / \mathrm{mL}$. 
Table 7. The phytochemicals results showing presence (+) and absence (-) in different extracts of both plants.

\begin{tabular}{|c|c|c|c|c|c|}
\hline & Phytochemicals & n-hexane & $\mathrm{DCM}$ & Ethanol & Water \\
\hline \multirow{7}{*}{ Euphorbia helioscopia } & Alkaloids & + & - & + & + \\
\hline & Tannins & + & + & + & + \\
\hline & Flavonoids & - & + & + & + \\
\hline & Steroids & - & + & - & + \\
\hline & Reducing Sugars & + & - & - & + \\
\hline & Saponins & + & + & + & + \\
\hline & Anthraquinones & + & + & - & - \\
\hline \multirow{7}{*}{ Rumex dentatus } & Alkaloids & - & + & + & + \\
\hline & Tannins & - & + & + & + \\
\hline & Flavonoids & + & - & + & - \\
\hline & Steroids & + & + & + & - \\
\hline & Reducing sugars & - & - & - & + \\
\hline & Saponins & - & - & + & - \\
\hline & Anthraquinones & - & + & - & - \\
\hline
\end{tabular}

recent years. Scientific and pharmaceutical communities have recently paid the attention to medicinal plants as the medicines prepared from the plants are safe with lesser toxic effects when used in adequate amounts (Ahmad \& Beg, 2001). The antibacterial and antifungal activities against different strains validate the effectiveness of bioactive constituents present in both plants.

Our results also validate that many bioactive constituents are extracted from both the plants in increasing polarity of the solvents used. In our study, antimicrobial activities of both the plants present the highest percentage inhibition against tested organisms in an increasing order of polarity of the solvent used i.e., n-hexane $<$ DCM $<$ ethanol $<$ water. Hence, water and ethanolic extracts show better antimicrobial activities which can be shown by their comparative values of percentage zones of inhibition. However, DCM extract also exhibited fairer antimicrobial activity than that the n-hexane extract. This can also be accredited to the presence of soluble polyphenolic and phenolic compounds. Similar findings were reported on high antibacterial activities by Rahmoun et al. and Vlachos et al. (PérezLópez et al., 2008; Rahmoun et al., 2012; Vlachos et al., 1996). The lack or lesser antimicrobial activity observed in some extracts is not astonishing, as it can be accredited to the presence of lesser amounts of bioactive compounds particularly in case of n-hexane and DCM. Reports suggest that antimicrobial activity results as the components in the extracts cross the cell membranes, interacts with its proteins and enzymes which generates the flux of protons to the external of the cell. This results in cellular changes and eventually their death (Balakumar et al., 2011). The antimicrobial activity of the plants is the result of the disruption of the permeability barrier of bacterial membrane (Cowan, 1999).

Scientists have discovered that higher polarity of the solvent will help in efficient antioxidants from the plants. For instance, according to a report, methanol, which is a high polarity solvent for plant extraction has a greater effect as antioxidants. Likewise, ethanolic extracts of Ivorian plants possess greater amount of phenolics as compared to water, methanol and acetone (Koffi et al., 2010). Likewise, our findings follow the same trend. The characteristic of plant extracts to scavenge the free radicals has been investigated by different assays (DPPH, hydroxyl and superoxide radical scavenging assays). The actual mechanism of an antioxidant is to inhibit the production of reactive oxygen species (ROS) or free radical scavenging. Therefore, any single method cannot comprehend the antioxidant capacity of the plant extracts. Hence, more than single methods are used (Aruoma, 2003).

Our results show that water extract of the E. helioscopia possess higher scavenging of DPPH, hydroxyl and superoxide radicals in a concentration dependent manner. This can be attributed to the presence of phenolic compounds in water extract. Similarly, Rumex dentatus extracts also exhibited better antioxidant activities, however, the higher percentage scavenging was shown by an ethanolic extract against DPPH radicals and water extract against hydroxyl and superoxide radicals at the equal concentration $(500 \mu \mathrm{g} / \mathrm{mL})$ using Vc as a standard. In addition to this, antitumor activities of the different extracts of both the plants validated that percentage inhibition of tumors are maximum for water extract of E. helioscopia and ethanolic extract for Rumex dentatus in a concentration-dependent manner. These results validated that both of the plants possess antitumor ability. The phytochemical screening shows the presence or absence of various phytoconstituents in the extracts of both the plants that may contribute to their bioactivities.

It can be determined from our findings that medicinal plants contain various bioactive components that have the ability to fight against pathogens. This research could be helpful in the development of novel drugs which are a greater demand these days. The selection of solvent for efficient extraction of medicinal plants may play a greater role in the evaluation of their therapeutic potential more efficiently. However, further research is still needed to establish a correlation between the better antioxidant, antitumor and antimicrobial properties of extracts of these plants in in vivo studies.

\section{Conclusions}

E. helioscopia and $R$. dentatus are two important medicinal plants with significant bioactivities. The polarity of the extracting solvents plays a vital role in contributing bioactivities of both plants used in our study. Our research investigated antimicrobial, in vitro antioxidant, and antitumor activities of both plants in different solvents according to the increasing polarity. Our findings suggest efficient bioactivities of water and ethanolic extracts which are more 
polar than DCM and n-hexane that may result in the extraction of effective constituents from both plants. The efficient antimicrobial and antitumor activities could be ascribed to the presence of bioactive constituents of the plants. The results from this study hence can be used as groundbreaking in the further examination, particularly in characterizing and isolating the dynamic principles that contribute to the efficient bioactivities. In the future, work is further needed to confirm the effectiveness of these two plant extracts in in vivo studies. Our study confirms that many novel drugs from both these medicinal plants can be manufactured with greater pharmacological properties.

\section{Conflict of interest}

All the contributing authors declare no conflicts of interest.

\section{Acknowledgements}

This was a collaborative study supported by Institute of Chemical Sciences (ICS), University of Peshawar, Pakistan and National Science Foundation of China (NSFC). The authors acknowledge the support of both Institutes.

\section{References}

Ahmad, I., \& Beg, A. Z. (2001). Antimicrobial and phytochemical studies on 45 Indian medicinal plants against multi-drug resistant human pathogens. Journal of Ethnopharmacology, 74(2), 113-123. http://dx.doi.org/10.1016/S0378-8741(00)00335-4. PMid:11167029.

Altemimi, A., Lakhssassi, N., Baharlouei, A., Watson, D. G., \& Lightfoot, D. A. (2017). Phytochemicals: Extraction, isolation, and identification of bioactive compounds from plant extracts. Plants, 6(4), 42. http:// dx.doi.org/10.3390/plants6040042. PMid:28937585.

Aruoma, O. I. (2003). Methodological considerations for characterizing potential antioxidant actions of bioactive components in plant foods. Mutation Research. Fundamental and Molecular Mechanisms of Mutagenesis, 523-524, 9-20. http://dx.doi.org/10.1016/S0027-5107(02)00317-2. PMid:12628499.

Ashraf, A., Sarfraz, R. A., Rashid, M. A., \& Shahid, M. (2015). Antioxidant, antimicrobial, antitumor, and cytotoxic activities of an important medicinal plant (Euphorbia royleana) from Pakistan. Journal of Food and Drug Analysis, 23(1), 109-115. PMid:28911432.

Balakumar, S., Rajan, S., Thirunalasundari, T., \& Jeeva, S. (2011). Antifungal activity of Ocimum sanctum Linn.(Lamiaceae) on clinically isolated dermatophytic fungi. Asian Pacific Journal of Tropical Medicine, 4(8), 654-657. http://dx.doi.org/10.1016/S19957645(11)60166-1. PMid:21914546.

Batool, R., Aziz, E., Mahmood, T., Tan, B. K., \& Chow, V. T. (2018). Inhibitory activities of extracts of Rumex dentatus, Commelina benghalensis, Ajuga bracteosa, Ziziphus mauritiana as well as their compounds of gallic acid and emodin against dengue virus. Asian Pacific Journal of Tropical Medicine, 11(4), 265. http://dx.doi. org/10.4103/1995-7645.231466.

Blois, M. S. (1958). Antioxidant determinations by the use of a stable free radical. Nature, 181(4617), 1199-1200. http://dx.doi. org/10.1038/1811199a0.

Boots, A. W., Haenen, G. R., \& Bast, A. (2008). Health effects of quercetin: from antioxidant to nutraceutical. European Journal of Pharmacology, 585(2-3), 325-337. http://dx.doi.org/10.1016/j. ejphar.2008.03.008. PMid:18417116.

Carron, E. A., Maran, J. M., Montero, L., Fernandozalgo, A., \& Dominguez, A. (1987). Antimicrobial properties of some extracts obtained from some Mediterranean plants of medicinal value. Plantes Medicinales et Phytotherapie, 21, 195-202.
Cowan, M. M. (1999). Plant products as antimicrobial agents. Clinical Microbiology Reviews, 12(4), 564-582. http://dx.doi.org/10.1128/ CMR.12.4.564. PMid:10515903.

Humeera, N., Kamili, A. N., Bandh, S. A., Amin, S., Lone, B. A., \& Gousia, N. (2013). Antimicrobial and antioxidant activities of alcoholic extracts of Rumex dentatus L. Microbial Pathogenesis, 57, 17-20. http://dx.doi.org/10.1016/j.micpath.2013.02.001. PMid:23415966.

Koffi, E., Sea, T., Dodehe, Y., \& Soro, S. (2010). Effect of solvent type on extraction of polyphenols from twenty three Ivorian plants. Journal of Animal and Plant Sciences, 5(3), 550-558.

Liu, S. Y., Sporer, F., Wink, M., Jourdane, J., Henning, R., Li, Y. L., \& Ruppel, A. (1997). Anthraquinones in Rheum palmatum and Rumex dentatus (Polygonaceae), and phorbol esters in Jatropha curcas (Euphorbiaceae) with molluscicidal activity against the schistosome vector snails Oncomelania, Biomphalaria, and Bulinus. Tropical Medicine \& International Health, 2(2), 179-188. http:// dx.doi.org/10.1046/j.1365-3156.1997.d01-242.x. PMid:9472303.

Maoulainine, L. B. M., Jelassi, A., Hassen, I., Ould, O. M. S., \& Boukhari, A. (2012). Antioxidant proprieties of methanolic and ethanolic extracts of Euphorbia helioscopia (L.) aerial parts. International Food Research Journal, 19(3), 1125.

Muhammad, Q., Gilani, S. N., Shahid, F., Abdur, R., Rifat, N., \& Samreen, P. (2012). Preliminary comparative phytochemical screening of Euphorbia species. American-Eurasian Journal of Agricultural \& Environmental Sciences, 12(8), 1056-1060.

Nisa, H., Kamili, A. N., Bandh, S. A., Shajr-ul-Amin, Lone, B. A., \& Parray, J. A. (2013). Phytochemical screening, antimicrobial and antioxidant efficacy of different extracts of Rumex dentatus L.-a locally used medicinal herb of Kashmir Himalaya. Asian Pacific Journal of Tropical Disease, 3(6), 434-440. http://dx.doi.org/10.1016/S2222-1808(13)60097-3.

Öztürk, H., Kolak, U., \& Meric, C. (2011). Antioxidant, anticholinesterase and antibacterial activities of Jurinea consanguinea DC. Records of Natural Products, 5(1), 43.

Padalia, R. C. (2012). Medicinal and aromatic plants: chemical goldmines. Medicinal \& Aromatic Plants, 1, e113.

Pérez-López, A., Orozco-Hayek, M., Rivas-Galindo, V., \& De Torres, N. W. (2008). Experimental design to determine the factors affecting the preparation of extracts for antibacterial use. Natural Product Communications, 3(3), 1934578X0800300. http://dx.doi. org/10.1177/1934578X0800300311.

Rahmoun, N. M., Boucherit-Otmani, Z., Boucherit, K., Benabdallah, M., Villemin, D., \& Choukchou-Braham, N. (2012). Antibacterial and antifungal activity of lawsone and novel naphthoquinone derivatives. Medecine et Maladies Infectieuses, 42(6), 270-275. http:// dx.doi.org/10.1016/j.medmal.2012.05.002. PMid:22682997.

Soobrattee, M. A., Bahorun, T., Neergheen, V. S., Googoolye, K., \& Aruoma, O. I. (2008). Assessment of the content of phenolics and antioxidant actions of the Rubiaceae, Ebenaceae, Celastraceae, Erythroxylaceae and Sterculaceae families of Mauritian endemic plants. Toxicology in Vitro, 22(1), 45-56. http://dx.doi.org/10.1016/j.tiv.2007.07.012. PMid:17911003.

Suffredini, I. B., Sader, H. S., Gonçalves, A. G., Reis, A. O., Gales, A. C., Varella, A. D., \& Younes, R. N. (2004). Screening of antibacterial extracts from plants native to the Brazilian Amazon Rain Forest and Atlantic Forest. Brazilian Journal of Medical and Biological Research, 37(3), 379-384. http://dx.doi.org/10.1590/S0100-879X2004000300015. PMid:15060707.

Vlachos, V., Critchley, A. T., \& Von Holy, A. (1996). Establishment of a protocol for testing antimicrobial activity in southern African macroalgae. Microbios, 88(355), 115-123. PMid:9131809.

Waheed, K., Muhammad, S. K., Shomaila, A., Muhammad, Z., Izhar, U., \& Ullah, S. (2020). Antimicrobial activity and phytochemical screening of Euphorbia helioscopia. Planta Daninha, 38, e020213727. http://dx.doi.org/10.1590/s0100-83582020380100011. 